\title{
METABOLIC AND NUTRITIONAL INTERFACES IN \\ POLYCYSTIC OVARY SYNDROME: CONSIDERATIONS \\ REGARDING OBESITY AND DIETARY MACRONUTRIENTS
}

\author{
INTERFACES NUTRICIONALES Y METABÓLICAS EN EL \\ SÍNDROME DEL OVARIO POLICÍSTICO: EL PAPEL DE LA \\ OBESIDAD Y DE LOS MACRONUTRIENTES DE LA DIETA
}

\author{
Fernanda Rodrigues de O. P. (1), Camila Cremonezi J. (1), Flávia Troncon R. (1), \\ Izabel de Arruda L. (1), Rosa Wanda D. (2), Paula Garcia Ch. (2)
}

(1) Postgraduate Program of Medical Sciences, Department of Internal Medicine, Faculty of Medicine of Ribeirão Preto, University of São Paulo, Ribeirão Preto, SP, Brazil.

(2) Department of Internal Medicine, Faculty of Medicine of Ribeirão Preto,

University of São Paulo, Ribeirão Preto, SP, Brazil.

\begin{abstract}
RESUMEN
El Síndrome del Ovário Poliquístico (SOP) es un desorden endocrino que ocurre entre las mujeres en edad reproductiva. Se caracteriza por irregularidad menstrual, anovulación crónica, infertilidad e hiperandrogenismo. La prevalencia de la obesidad es alta entre mujeres con el SOP y sus causas aún no están esclarecidas. Anormalidades en el gasto energético y en la respuesta disminuida de las hormonas gastrointestinales responsables por el control de la ingestión alimentaria, especialmente la grelina son posibles hipótesis para explicar la obesidad asociada al SOP. Los efectos de la composición dietética en el SOP aún están poco explorados. Es posible que los ácidos grasos poliinsaturados (PUFA) mejoran la sensibilidad insulínica y que dietas hiperproteicas potencializan la pérdida de peso y mejoran la función reproductiva. Sin embargo, las evidencias actuales no son suficientes para determinar las características dietéticas mas adecuadas para el SOP. La conducta dietética debe enfocar la pérdida de peso con dietas nutricionalmente completas y balanceadas.
\end{abstract}

Palabras clave: síndrome del ovario poliquístico; obesidad; grelina; macronutrientes de la dieta.

Este trabajo fue recibido el 19 de Enero de 2009 y aceptado para ser publicado el 12 de Junio de 2009.

\section{INTRODUCTION}

Polycystic ovary syndrome (PCOS) is one of the most common endocrine disorders among women, affecting $5-10 \%$ of women at reproductive age (1). The syndrome was first defined in 1935 by Stein and Leventhal based on the observation of a set of symptoms such as amenorrhea, hirsutism and obesity in women whose ovaries were enlarged and contained multiple follicular cysts (2). However, reference to the influence of obesity on menstruation had been observed as early as in the writings of Hippocrates. In his assay about "the influence of climate, water supply and health situation", he described women with altered reproductive function as follows: "the girls become flaccid and pudgy... persons with this constitution cannot generate many children ... fat and flaccidity are the culprits. The uterus is unable to receive semen and the women menstruate little and in an infrequent manner" (3).

The PCOS is a syndrome and, as such, it's necessary use more than a single diagnostic criterion for clinical diagnosis. In accordance with the consensus of Rotterdam (2003), the most widely accepted for the diagnosis of PCOS, it's necessary the presence of at least two of the three features: oligo- or anovulation, clinical or biochemical evidence of androgen excess and polycystic ovaries. Moreover, it's necessary the exclusion of other medical conditions that cause irregular menstrual cycles and androgen excess such congenital adrenal 
hyperplasia, Cushing's syndrome, hyperprolactinemia or ovarian neoplasm (4).

It's important to consider that the diagnostic criteria for PCOS have not been fully standardized due to the intrinsic characteristics of the syndromes, whose symptoms are highly heterogeneous. In its classical form, the characteristics more frequently presented by women with PCOS are menstrual irregularity of oligo/ amenorrhea type, chronic anovulation (80\%), infertility, and clinical or laboratory hyperandrogenism, which may be associated with hirsutism (60\%), acne (30\%) and obesity (40\%) (5-7). The disorder also is a strong independent risk factor for the development of impaired glucose tolerance and type II diabetes $(8,9)$ and includes various characteristics of metabolic syndrome such as obesity, abdominal obesity and insulin resistance (IR), thus being strongly related to a higher risk of developing cardiovascular diseases (10).

In view of the interfaces existing between PCOS, obesity and nutrition, the objective of the present study was to explore aspects related to the possible causes of the high prevalence of obesity among women with PCOS and to the role of diet composition in the treatment of this disease.

\section{OBESITY AND POLYCYSTIC OVARY SYNDROME}

There are strong evidences indicating the familiar aggregation in PCOS, suggesting that genetic factors play a important role in the development of this syndrome $(11,12)$. Studies of families with PCOS cases have evidences of heritability of hyperandrogenaemia and hyperinsulinaemia, and first-degree relatives of women with PCOS present increase incidence of features such oligomenorrhea, polycystic ovaries and androgen excess, beyond the metabolic alterations such insulin resistance type II diabetes and lipid abnormalities $(13,14)$. Therefore, familial history, indicating the genetic risk, must be considered as an important risk factor for the development of PCOS. However, the heterogeneity of phenotypic features in different and within the same families underscores the importance of the environmental contribution in the manifestation of this syndrome $(11,12)$, especially of obesity.

The prevalence of obesity is high in all studies of women with PCOS and obese women with PCOS have higher rates of hirsutism and greater irregularities of the menstrual cycle than eutrophic women with the same disease (15). About 38-88\% of women with PCOS are estimated to be overweight or obese (16), with the history of weight gain usually preceding the onset of oligomenorrhea and hyperandrogenism, suggesting a pathogenic role of obesity in the development of the syndrome (17). A study was conducted on premenopausal overweight and obese Spanish women in order to assess the presence of PCOS and its characteristics. Of the 113 women who participated in the study, 28.3\% (CI 20-36.9\%) had a diagnosis of PCOS, with no variation in prevalence according to different degrees of obesity. The prevalence of this syndrome among these overweight Spanish women was significantly higher than among women of adequate weight, being approximately 5.5\% (14). Guzick (2007) pointed out that $66 \%$ of women with PCOS presented excess weight, characterized by overweight $(24 \%)$ and obesity (42\%) (18). This value was significantly higher than that for the general population (16), with a predominance of the phenotype of abdominal obesity associated with hyperandrogenic state, IR and compensatory hyperinsulinaemia (16-19). Insulin resistance was estimated to be present in 50 to $70 \%$ of them (20).

The causes of the increased prevalence of obesity in PCOS have not been fully elucidated in the literature. Some authors suggest that there may be abnormalities in energy expenditure, especially in postprandial thermogenesis (21). Robinson et al (1992) showed that there was no difference in resting energy expenditure but that the PCOS group had a reduced postprandial thermogenesis $(-42 \mathrm{KJ})$ compared to a control group matched for body weight, with an estimated weight gain of $1.9 \mathrm{~kg}$ body fat per year if this deficit in energy expenditure was maintained on a long-term basis (22). However, Segal \& Dunaif (1990) did not detect differences in resting energy expenditure or in thermogenesis between women with PCOS and controls without PCOS, paired for body weight (23).

\section{OBESITY AND POLYCYSTIC OVARY SYNDROME: THE ROLE OF GHRELIN}

There also seems to be a lower postprandial response of the gastrointestinal hormones responsible for the control of food intake. Among healthy persons, the levels of ghrelin, an important peptide that regulates food consumption, body weight, pancreatic and endocrine function, glucose metabolism, and ovarian function, increase during the preprandial period and stimulate hunger and food ingestion by acting on the hypothalamic nucleus (24-25).

After a meal is started, both the presence of nutrients in the intestine and the metabolic response to eating lead to suppression of ghrelin which results in a change in appetite. Additional factors such as leptin, adiponectin, cholecystokinin, peptide YY, fat-free mass and androgens may play a role in the regulation of energy homeostasis, of appetite and of ghrelin concentration (24-25). 
Reduced basal ghrelin levels have been detected in women with excess weight and PCOS (24-27). Pagotto et al (2002) reported that obese women with PCOS have significantly lower ghrelin levels than obese women without the pathology (27). The reduction in the postprandial levels of ghrelin is lower in obese than in lean persons and in obese patients with PCOS than in obese women without PCOS (24-25). In a study conducted on 33 women with PCOS and with excess weight, a negative and significant correlation $(\mathrm{r}=-0.45 ; \mathrm{p}<0.01)$ was detected between basal ghrelin concentrations and body mass index (BMI), suggesting that excess fat mass may reduce the levels of this hormone (28). A common finding reported in the literature is the negative correlation existing between insulin resistance and plasma ghrelin concentrations $(26,27,29)$. Schöfl et al (2002) detected similar ghrelin concentrations in insulin-sensitive women with PCOS and in healthy controls and significantly reduced levels in women with PCOS and IR, suggesting a connection between insulin sensitivity and ghrelin (26). There is a study suggesting that the primary association would be between ghrelin and androgens rather than between ghrelin and insulin (30).

The change in ghrelin concentrations is seen as an important consequence of obesity and may influence the regulation of body weight by impairing the stimulus to end eating, affecting the size of the meal consumed. Moran et al (2004) observed that women with PCOS had lower satiety and greater postprandial hunger after a test meal, suggesting that they had fewer defenses against overeating and greater difficulty in ending a meal than controls without this syndrome (24). Abnormalities in appetite regulation may possibly be more prevalent among women with PCOS and IR than among women without IR (25).

\section{WEIGHT LOSS AND POLYCYSTIC OVARY SYNDROME}

The importance of the relationship between obesity and PCOS is reflected on the recommendations for the treatment of this syndrome, whose main objective is the reduction of weight and of abdominal fat in order to normalize serum androgen levels, to reduce insulin resistance and to restore reproductive function. Short-term weight loss has been successful in reducing insulin resistance and restoring ovulation and fertility $(1,10,31,32)$, resulting in strong recommendations of care with weight among women with PCOS (33).

In a study of the effect of weight loss on the ovarian functionality of obese women with PCOS, Tolino et al (2005) observed that the patients who lost more than $5 \%$ of their initial body weight presented a significantly greater improvement of menstrual dysfunction and of reproductive function than women who lost less than $5 \%$ of their initial body weight. In addition, patients with a weight loss of more than $5 \%$ presented a significant improvement in the levels of free testosterone, fasting insulin and hirsutism compared to initial values, a fact that was not observed in patients who lost less than $5 \%$ of their initial body weight (34). Another study also carried out in order to assess the improvement of ovarian physiology and of anthropometric indices of overweight/obese women with PCOS reported positive results regarding both anthropometric parameters and ovarian physiology and fertility in women with PCOS and excess weight (35).

\section{DIET AND POLYCYSTIC OVARY SYNDROME: DOES THE NUTRITIONAL COMPOSITION OF THE DIET MAKE A DIFFERENCE?}

The main focus of dietary studies on women with PCOS is on the effect of energy restriction on weight loss. The specific effect of diet composition in PCOS have only recently started to receive more attention. The role of diet composition in infertility is still little explored, but current evidence suggests that dietary factors influence insulin sensitivity, play an important role in the etiology of some forms of infertility (36).

Experimental evidence suggests that polyunsaturated fatty acids (PUFA) improve insulin sensitivity in peripheral tissues and reduce insulin secretion by the pancreas. In addition, PUFA and their subproducts have the ability to activate PPAR- $\square$, being useful for the treatment of insulin resistance in PCOS (37).

PPAR $-\gamma$ is a transcriptional gene that regulates metabolism whose activity is directly modulated by dietary lipids (38). PPAR- $\gamma$ activation improves ovulatory function in women with POS and some dietary fatty acids may affect PPAR- $\gamma$ in different ways. Unsaturated fatty acids may bind to PPAR- $\gamma$, but their effects differ according to cis or trans isomers $(37,39)$. A high intake of unsaturated cis fatty acids is associated with lower concentrations of inflammatory markers and a lower risk of type II diabetes mellitus, in addition to an improvement of the endocrine and metabolic characteristics of women with PCOS. In order to assess the relation between the dietary intake of some nutrients and fertility, a prospective cohort study was conducted on 18.555 premenopausal women with no history of infertility, with the detection of 438 cases of ovulatory infertility. The results showed that fat intake and total cholesterol were not related to ovulatory infertility but that there was a positive association between the intake of trans fatty acids and the risk of infertility. Total daily energy 
intake above $2 \%$ in the form of unsaturated trans fatty acids was associated with a $94 \%$ risk of the occurrence of ovulatory infertility (CI 22-208\%). The isocaloric replacement of monounsaturated fatty acids (MUFA) with trans fatty acids significantly increased the risk of infertility $(\mathrm{RR}=2.32$; CI1.09-4.87; $\mathrm{p}=0.028)$, the same being observed for PUFA $n-6$ (RR $=1.79$; CI1.11-2.89; $\mathrm{p}$ $<0.02)$ and for carbohydrates $(\mathrm{RR}=1.73$; CI1.09-2.73). It was concluded that unsaturated trans fatty acids can increase the risk of ovulatory infertility when consumed in place of carbohydrates or of unsaturated fatty acids (MUFA and PUFA) (38).

The effect of replacing dietary fat with PUFA for 3 months (with no change in total dietary fat content) on the metabolic and endocrine profile was assessed in women with PCOS $(n=17)$. The results showed a significant reduction in body weight, in free fatty acid levels and in total cholesterol and an increase in plasma levels of linoleic acid and alpha-linolenic acid. No improvement was observed in serum testosterone, sex hormone binding protein (SHBG), luteinizing hormone (LH), or follicle stimulating hormone (FSH). In addition, there was a significant increase in fasting glycemia and in the area under the curve for glucose during the oral glucose tolerance test, with no change in insulin. However, despite the improvements observed, there still is insufficient scientific evidence to recommend the intake of dietary PUFA supplements, especially in insulin-resistant populations (36).

Douglas et al (2006) conducted a study in order to determine whether diets with the same energy content and a greater proportion of MUFA (17\%) or poor in carbohydrates (43\%) would improve insulin sensitivity and reduce circulating insulin levels in women with PCOS compared to a standard diet (56\% carbohydrates, $31 \%$ fat and $16 \%$ protein). The subjects consumed 3 types of diets (rich in MUFA, poor in carbohydrates, and standard), each for only 16 days, with a 3 week interval between diets. Fasting insulin levels were lower in the carbohydrate-poor diet compared to the standard diet and the insulin response to an acute glucose dose was lower in the carbohydrate-poor diet than in the MUFArich diet. Serum glucose and reproductive hormone levels did not differ between the dietary interventions. The results suggest a possible beneficial effect of the diet with a reduced carbohydrate content $(43 \%)$ on the metabolic profile of women with PCOS (39). However, it should be remembered that, in addition to having a reduced carbohydrate content, the diet was rich in fibers (29 g) and contained 17\% PUFA, 18\% MUFA, only $8 \%$ saturated fat, and $83 \mathrm{mg}$ cholesterol. This dietary composition may have been of help regarding the better physiological benefits observed .

Dietary strategies for weight loss usually recommend the use of fat-poor diets, which facilitate energy restriction and reduce the risks of cardiovascular diseases. However, over the last few years there has been increased interest in protein-rich and carbohydrate-poor diets for the potentiation of weight loss and also for the improvement of metabolic and reproductive parameters (40-41). The increased intake of dietary protein as a way of increasing weight loss is based on the greater power of protein to induce satiety compared to carbohydrates and fats, as well as improving insulin sensitivity (42).

Clinical studies have provided evidence that ad libitum protein-rich diets generate a greater weight loss in overweight individuals over a period of 6 months than carbohydrate-rich diets. The main physiological explanation for this findings would be the greater satiety induced by the high protein content of the diet (42). In addition to producing weight loss, these diets seem to have beneficial effects on body composition, on serum lipid levels and on glucose homeostasis.

A study assessed the effects of two diets containing different carbohydrate/protein ratios on weight loss, body composition and blood lipids of adult women with excess weight. The first group consumed a diet with a 3.5 carbohydrate/protein ratio (68 g protein) and the second consumed a diet with a 1.4 ratio ( $125 \mathrm{~g}$ protein). The diets contained equal amounts of calories and fats ( $\sim 50 \mathrm{~g} /$ day). After 10 weeks, weight loss did not differ between groups $(6.96+1.36 \times 7.53+1.44 \mathrm{~kg})$. However, the changes in body composition, expressed by the fat loss/lean mass loss ratio, showed that the second group had a greater loss of fat than of lean mass compared to the first group (a ratio of $6.3+1.2 \times 3.8+0.9 \mathrm{~kg}$ ). Both groups presented reductions in total cholesterol levels, but only the second one obtained significant reductions in triglyceride levels (21\%) and in the triglyceride/ HDL-c ratio $(23 \%)$. The women of this same group also reported greater satiety with the protein-rich diet (43). Kasim-Karakas et al (2007) evaluated the effects of acute protein administration with those of glucose (OGTT) challenges on hormones related with hunger insulin and ghrelin. For the OGTT, the participants ingested $75 \mathrm{~g}$ glucose and for the protein challenge, they ingested $75 \mathrm{~g} 98 \%$ pure, intact whey protein isolate containing no carbohydrate. The glucose and the protein drinks were euvolemic and eucaloric. The results showed that glucose ingestion caused larger fluctuations in blood glucose and more hyperinsulinemia than did protein and both glucose and protein suppressed ghrelin. However, after glucose ingestion, ghrelin returned to baseline by $4 \mathrm{~h}$ and increased to at $5 \mathrm{~h}$, what it was 
not observed after the protein challenge, when ghrelin remained below the baseline even at $5 \mathrm{~h}$. These results show that glucose ingestion caused significantly more hiperinsulinemia than did protein, and that protein intake suppressed ghrelin significantly longer than did glucose. This suggests a prolonged satietogenic effect of protein intake, providing mechanistic support for increasing protein intake and restricting the simple sugar intake in a PCOS diet (44).

These studies demonstrate the benefits of a proteinrich diet regarding body composition, blood lipids, glucose homeostasis, as well as satiety in overweight women during the weight loss process. Similar results were obtained in a study conducted on hyperinsulinemic and normoglycemic obese men. Two groups of subjects consumed different low-energy diets that provided $80 \%$ of resting energy expenditure. One received a highprotein (45\%) and low-carbohydrate (25\%) diet and the other a higher-carbohydrate (58\%) and lower-protein $(12 \%)$ diet, with both diets containing the same amount of fat $(30 \%)$. The results showed a greater weight loss in the group receiving more dietary protein $(8.3+0.7 \mathrm{x}$ $6.0+0.6 \mathrm{~kg}, \mathrm{p}<0.05)$. Serum levels of total cholesterol, triglycerides and LDL-c were significantly reduced in both groups, but a significant reduction in HDL-c occurred only in the group receiving more protein. Fasting serum insulin levels were reduced in both groups but reached normal levels only in the group receiving the high-protein diet (45).

To assess the effects of isocaloric carbohydrate replacement with protein in women with PCOS and overweight, two restricted-energy diets were tested for a period of 12 weeks, one of them protein-rich (30\% protein, $40 \%$ carbohydrates and $30 \%$ fat) and the other protein-poor (15\% protein, $55 \%$ carbohydrates and $30 \%$ fat). The increase in the number of pregnancies, the improvement in menstrual cycle, in lipid profile and in insulin resistance and the reduction of body weight $(7.5 \%)$ and abdominal fat $(12.5 \%)$ occurred independently of diet composition (41). These results suggest that the improvements observed in the reproductive, cardiovascular and metabolic parameters can be attributed to the improved insulin resistance and fasting insulinemia (a consequence of weight reduction), and were independent of diet composition.

\section{FINAL CONSIDERATIONS}

There is a strong relation between PCOS and obesity. Therefore, the main objective for the treatment of this syndrome is weight loss, with the intention to improve or to normalize the hormonal and metabolic alterations. Weight losses between $5-10 \%$ shown success in improvement the IR, the menstrual disorders and the hyperandrogenism, leading the restoration of the ovulation and fertility $(1,10,31,34,35)$.

Current evidence is still insufficient to determine an optimum diet composition for patients with PCOS, especially on a long-term basis, but some directives regarding a dietary conduct can be inferred. A modification of life style is the first form of treatment of PCOS, involving weight loss and the regular practice of physical activity. Weight loss should be achieved by adopting healthier dietary habits and nutritionally complete and balanced diets. The dietary composition should give priority to a low saturated and trans fat content, should be rich in poly- and monounsaturated fats, have a low glycemic index (46), and be rich in fibers and poor in energy $(20,33,41)$.

There still is no clear position regarding the protein content of the diet, with more consistent results of longerlasting investigations being needed. It should be pointed out that no nutritional manipulation maintains its validity in diets strongly deviating from the usual eating habits of each group and that the best diet is the one definitively adopted or used for longer periods of time, permitting more sustainable weight losses.

\section{ABSTRACT}

Polycystic ovary syndrome (PCOS) is one of the most common endocrine disorders among women at reproductive age. Its classical form is characterized by menstrual irregularities, chronic anovulation, infertility, and hyperandrogenism. The prevalence of obesity is high among women with POS and its causes have not been fully clarified. Hypotheses have been raised suggesting the possible presence of both abnormal energy expenditure and a reduced response of the gastrointestinal hormones responsible for the control of food ingestion, especially ghrelin. The specific effects of diet composition on POS have been little explored. It has been suggested that polyunsaturated fatty acids may improve insulin sensitivity and that high-protein diets may potentiate weight loss and improve reproductive function. However, current evidence is insufficient to determine the optimum composition of a diet for POS patients. The dietary conduct should focus on weight loss to be achieved with nutritionally complete and balanced diets.

Key words: polycystic ovary syndrome; obesity; ghrelin; dietary macronutrients.

Dirigir la correspondencia a:

Profesora

Fernanda Rodriguez de O. P.

Postgraduate Program of Medical Sciences, 
Department of Internal Medicine,

Faculty of Medicine of Ribeirão Preto,

University of São Paulo,

Ribeirão Preto,

SP, Brazil.

\section{REFERENCES}

1. The Thessalomiki ESHRE/ASRM-Sponsored PCOS Consensus Workshop Group. Consensus on infertility treatment related to polycystic ovary syndrome. Hum Reproduct 2008; 23(3):462-477.

2. Stein IF, Leventhal ML. Amenorrhoea associated with bilateral polycystic ovaries. Am J Obstet Gynecol 1935; 29:181-191.

3. Franks S, Robinson S, Willis DS. Nutrition, insulin and polycystic ovary syndrome. Rev Reproduct 1996; 1:47-53.

4. The Rotterdam ESHRE/ASRM-sponsored PCOS consensus workshop group. Revised 2003 consensus on diagnostic criteria and long-term health risks related to polycystic ovary syndrome (PCOS). Hum Reproduct 2004; 19(1): 41-47.

5. Speca S, Napolitano C, Tagliaferri G. The pathogenic enigma of polycystic ovary syndrome. J Ultrassom 2007:1-8.

6. Nacul A, Comim F, Spritzer PM. Aspectos neuroendócrinos na Síndrome dos Ovários Policísticos. Arq Bras Edocrinol Metab 2003; 47(4): 432-439.

7. Kuba VM, Cavalieri PM, Chistóforo AC, Junior RF, Caetano R, Coeli CM, Athayde A. Resistência insulínica e perfil metabólico em pacientes com síndrome dos ovários policísticos de peso normal e sobrepeso/obesidade. Arq Bras Endocrinol Metab 2006; 50(6):1026-1033.

8. Norman RJ, Masters L, Milner CR, Wang JX, Davies MJ. Relative risk of conversion from normoglycaemia to impaired glucose tolerance or non-insulin dependent diabetes mellitus in polycystic ovary syndrome. Hum Reprod 2001; 16 (9): 1995-8.

9. Ehrmann DA, Barnes RB, Rosenfield RL, Cavaghan MK, Imperial J. Prevalence of impaired glucose tolerance and diabetes in women with polycystic ovary syndrome. Diabetes Care 1999; 22: 141-146.

10. Barber TM, McCarthy MI, Wass JAH, Franks S. Obesity and polycystic ovary syndrome. Clin Endocrinol 2006; 65:137-145.

11. Unluturk U, Harmanci A, Kocaefe C, Yildiz BO. The Genetic Basis of the Polycystic Ovary Syndrome: A Literature Review Including Discussion of PPAR- $\gamma$. PPAR Res 2007, ID 49109, 1-23.

12. Dasgupta S, Mohan RB. Present status of understanding on the genetic etiology of polycystic ovary syndrome. J Postgrad Med 2008; 54 (2): 115-125.

13. Legro RS, Strauss JF. Molecular progress in infertility: polycystic ovary syndrome. Fertil Steril 2002; 78: 569-576.

14. Franks S, McCarthy M. Genetics of ovarian disorders: polycystic ovary syndrome. Rev Endo Metab Disord 2004; 5: 69-76.

15. Balen A, Michelmore K. What is polycystic ovary syndrome? Hum Reproduct 2002; 17(9): 22192227.

16. Alvarez-Blasco F, Botella-Carretero JI, San Milla JL, Escobar-Morreale HF. Prevalence and characteristics of the polycystic ovary syndrome in overweight and obese women. Arch Intern Med 2006; 23:2081-2086.

17. Pasquali R. Obesity, fat distribution and infertility. Maturitas 2006; 54:363-371.

18. Guzick DS. Ovulation induction management of PCOS. Clin Obstet Gynecol 2007; 50(1):255-266.

19. Gambineri A, Pelusi C, Vicennati V, Pagotto U, Pasquali R. Obesity and the polycystic ovary syndrome. Internat J Obes 2002; 26: 883-896.

20. Marsh K, Brand-Miller J. The optimal diet for women with polycystic ovary syndrome? British J Nutr 2005; 94:154-165.

21. Ravussin E, Acheson KJ, Vernet O, Danforth $\mathrm{E}$, Jequier E. Evidence that insulin resistance is responsible for the decreased thermogenic effect of glucose in human obesity. J Clin Invest 1985; 76:1268-1273.

22. Robinson S, Chan S-P, Spacey S, Anyaoku V, Johnston DG, Franks S. Post prandial thermogenesis is reduced in polycystic ovary syndrome and is associated with increased insulin resistance. Clin Endocrinol 1992; 36:537-543.

23. Segal KR, Dunaif A. Resting metabolic rate and postprandial thermogenesis in polycystic ovary syndrome. Internat J Obes 1990; 14:559-567.

24. Moran LJ, Noakes M, Clifton PM, Wittert GA, Tomlinson L, Galletly C, et al. Ghrelin and measures of satiety are altered in polycystic ovary syndrome but not differentially affected by diet composition. J Clin Endocr Metab 2004; 89:3337-3344.

25. Moran LJ, Noakes M, Clifton PM, Wittert GA, Le Roux CW, Ghatei MA, et al. Postprandial ghrelin, cholecystokinin, peptide YY, and appetite before and after weight loss in overweight women with and without polycystic ovary syndrome. Am J Clin Nutr 2007; 86:1603-10.

26. Schöfl C, Horn R, Schill T, Schlösser HW, Müller MJ, Brabant G. Circulating ghrelin levels in patients with polycystic ovary syndrome. J Clin Endocrinol 
Metab 2002; 87:4607-4610.

27. Pagotto U, Gambineri A, Vicennati V, Heiman ML, Tschöp M, Pasquali R. Plasma ghrelin, obesity, and the polycystic ovary syndrome: correlation with insulin resistance and androgen levels. J Clin Endocrinol Metab 2002; 87:5625-5629.

28. Orio Jr F, Lucidi P, Palomba S, Tauchmanova L, Cascella T, Russo T, et al. Circulating ghrelin concentrations in the polycystic ovary syndrome. J Clin Endocrinol Metab 2003; 88(2):942-945.

29. Wasko R, Komarowska H, Warenik-Szymankiewicz A, Sowinski J. Elevated ghrelin plasma levels in patients with polycystic ovary syndrome. Horm Metab Res 2004; 36:170-173.

30. Gambineri A, Pagotto U, Tschop M, Vicennati V, Manicardi E, Carcello A, et al. Anti-androgen treatment increases circulating ghrelin levels in obese women with polycystic ovary syndrome. J Endocrinol Invest 2003; 26:629-634.

31. Norman RJ, Davies MJ, Lord JL, Moran, LJ. The role of lifestyle modification in polycystic ovary syndrome. Trends in Endocrinology \& Metabolism 2002; 13(6):251-257.

32. Stamets K, Taylor DS, Kunselman A, Demers LM, Pelkman CL, Legro RS. A randomized trial of the effects of two types of short-term hypocaloric diets on weight loss in women with polycystic ovary syndrome. Fertility Sterility 2004; 81(3):630-637.

33. Moran L, Norman RJ. Understanding and managing disturbances in insulin metabolism and body weight in women with polycystic ovary syndrome. Best Practice \& Research. Clin Obstet Gynaecol 2004; 18(5):719 736.

34. Tolino A, Gambardella V, Caccavale C, D'ettore A, Giannotti F, D'Antó V, et al. Evaluation of ovarian functionality after a dietary treatment in obese women with polycystic ovary syndrome. European J Obstet Gynecol Reproductive Biol 2005; 119:87-93.

35. Crosignani PG, Colombo M, Vegetti W, Somigliana E, Gessati A, Ragni G. Overweight and obese anovulatory patients with polycystic ovaries: parallel improvements in anthropometrics indices, ovarian physiology and fertility rate induced by diet. Hum Reproduct 2003; 18(9):1928-1932.

36. Kasim-Karakas SE, Almario RU, Gregory L, Wong R, Todd H, Lasley BL. Metabolic and endocrine effects of a polyunsaturated fatty acid-rich diet in polycystic ovary syndrome. J Clin Endocrinol Metab 2004; 89(2):615-620.

37. Macias-Gonzalez M, Cardona F, Queipo-Ortuño M, Bernal R, Martin M, Tinahones FJ. PPAR- $\square$ mRNA expression is reduced in peripheral blood mononuclear cells after fat overload in patients with metabolic syndrome. J Nutr 2008; 138: 903-907.

38. Chavarro JE, Rich-Edwards JW, Rosner BA, Willett WC. Dietary fatty acid intakes and the risk of ovulatory infertility. Am J Clin Nutr 2007; 85:231-237.

39. Douglas CC, Gower BA, Darnell BE, Ovalle F, Oster RA, Azziz R. Role of diet in the treatment of polycystic ovary syndrome. Fertil Steril 2006; 85(3): 679-688.

40. Noakes M, Keogh JB, Foster PR, Clifton PM. Effect of an energy-restricted, high-protein, low-fat diet relative to a conventional high-carbohydrate, low-fat diet on weight loss, body composition, nutritional status, and markers of cardiovascular health in obese women. Am J Clin Nutr 2005; 81:1298-306.

41. Moran LJ, Noakes M, Clifton PM, Tomlinson L, Norman RJ. Dietary composition in restoring reproductive and metabolic physiology in overweight women with polycystic ovary syndrome. J Clin Endocrinol Metab 2003; 88: 812-819.

42. Astrup A, Grunwald GK, Melanson EL, Saris WHM, Hill JO. The role of low-fat diets in body weight control: a meta-analysis of ad libitum dietary intervention studies. Int J Obes 2000;24:1545-1552.

43. Layman DK, Shiue H, Sather C, Erickson DJ, Baum $\mathrm{J}$. Increased dietary protein modifies glucose and insulin homeostasis in adult women during weight loss. J Nutr 2003; 133: 405-410.

44. Kasim-Karakas SE, Cunningham WM, Tsodikov A. Relation of nutrients and hormones in polycystic ovary syndrome. Am J Clin Nutr 2007; 85: 688 $-694$.

45. Baba NH, Sawaya S, Torbay N, Habbal Z, Azar S, Hashim SA. High protein vs high carbohydrate hypoenergetic diet for the treatment of obese hyperinsulinemic subjects. Int J Obes 1999;23: 1202-1206.

46. Herriot AM, Whitcroft S, Jeanes Y. A retrospective audit of patients with polycystic ovary syndrome: the effects of a reduced glycaemic load diet. J Hum Nutr Diet 2008; 21:337-345. 